\title{
CRANIOLOGICAL MATERIALS OF THE LATE BRONZE AGE FROM THE BEREZOVSKY V KURGAN CEMETERY IN THE TRANS URALS ${ }^{1}$
}

\author{
Aleksey I. Nechvaloda \\ Ufa Federal Research Center of the Russian Academy of Sciences, Ufa, Russian Federation
}

\begin{abstract}
This paper is dedicated to discussion of craniological materials obtained from Berezovsky 5 burial mound in the southern Trans-Urals during archaeological excavations in 1994. The mound necropolis dates back to the Late Bronze Age ( $14^{\text {th }}$ to $13^{\text {th }} \mathrm{cc}$. BC) and relates to the Kozhumberdy stage in the Alakul development line of the Andronovo cultural community. Three researched skulls, two of them male and one female, originate from mound 6 of this burial site. The dental system of a young woman has undergone severe wear as a result of work activity. The craniological research of the female skull using Heincke formula made it possible to tentatively judge about its morphological affinity to skulls from the Laimberdy burial site and a combined skull set of the Akakul culture from the Trans-Urals. Basing on the female skull we have performed a graphic reconstruction of her appearance full face. The female skull shows some Mongoloid traits. Two male skulls failed to preserve their facial skeletons, except for braincases. The indicators of facial skeleton flattening at the orbital level can also testify to the presence of the Mongoloid component in their craniological type.

Key words: Late bronze, Alakul culture, combatancy type, anthropology, graphic the face of the skull, craniology, the Geynke formula.

Citation. Nechvaloda A.I., 2020. Craniological Materials of the Late Bronze Age from the Berezovsky V Kurgan Cemetery in the Trans Urals. The Lower Volga Archaeological Bulletin, vol. 19, no. 1, pp. 254-267. (in Russian). DOI: https://doi.org/10.15688/nav.jvolsu.2020.1.14
\end{abstract}

\section{КРАНИОЛОГИЧЕСКИЕ МАТЕРИАЛЫ ЭПОХИ ПОЗДНЕЙ БРОНЗЫ ИЗ БЕРЕЗОВСКОГО У КУРГАННОГО МОГИЛЬНИКА В ЗАУРАЛЬЕ ${ }^{1}$}

\author{
Алексей Иванович Нечвалода \\ Уфимский федеральный иследовательский центр РАН, г. Уфа, Российская Федерация
}

\begin{abstract}
Аннотация. Статья посвящена обсуждению краниологических материалов позднебронзового века из курганного могильника Березовский $\mathrm{V}$ в южном Зауралье, полученных в ходе раскопок 1994 года. Курганный некрополь датируется эпохой поздней бронзы XIV-XIII вв. до н.э. и относится к кожумбердынскому этапу алакульской линии развития андроновской культурной общности. Три исследованных черепа (два мужских и один женский) происходят из кург. 6 данного могильника. Зубная система молодой женщины подверглась сильному изнашиванию в результате использования в трудовой деятельности. Краниологическое исследование женского черепа с использованием формулы Гейнке позволило ориентировочно судить о его морфологической близости к черепам из могильника Лаимберды и к сборной серии черепов алакульской культуры из Зауралья. По черепу женщины была выполнена графическая реконструкция внешнего облика в норме анфас. Женский череп имеет налет монголоидности. Два мужских черепа не имели лицевого скелета, сохранилась только мозговая коробка. Показатели уплощенности лицевого скелета на орбитальном уровне также могут свидетельствовать о присутствии в их краниологическом типе монголоидного компонента.
\end{abstract}

Ключевые слова: поздняя бронза, алакульская культура, кожумбердынский тип, палеоантропология, графическая лица по черепу, краниология, формула Гейнке. 
Цитирование. Нечвалода А. И., 2020. Краниологические материалы эпохи поздней бронзы из Березовского V курганного могильника в Зауралье // Нижневолжский археологический вестник. Т. 19, № 1. С. $254-267$. DOI: https://doi.org/10.15688/nav.jvolsu.2020.1.14

\section{Введение}

Антропологические материалы были получены в результате археологических исследований, проведенных в 1994 г. экспедиционным отрядом Национального музея Республики Башкортостан в Кваркенском районе Оренбургской области. Березовский V курганный некрополь представляет собой десять курганов на левом берегу р. Урал, на первой надпойменной террасе. Всего было раскопано 3 курганных насыпи. Рассматриваемые ниже материалы происходят из 3 погребений кургана 6. Авторы раскопок отмечают, что в материалах Березовского могильника - как в погребальном обряде, так и в керамике прослеживается сочетание алакульских, федоровских и отчасти срубных традиций. Учитывая синкретический характер артефактов могильника, относят его к кожумбердынскому этапу алакульской линии развития андроновской культурной общности и датируют XIV-XIII вв. до н.э. [Федоров, Рафикова, 1996, с. 49-71].

\section{Методы}

Исследование черепа проводилось по методике, предложенной Р. Мартином [Martin, 1914], принятой в отечественной антропологии в модификации В.П. Алексеева и Г.Ф. Дебеца [Алексеев, Дебец, 1964]. Возраст устанавливался по степени облитерации швов черепа эктокрана [Алексеев, Дебец, 1964; Mendl, Lovejoy, 1985]. Выраженность (экспрессия) признаков полового диморфизма на черепе оценивалась с помощью балловых характеристик [Nemeskéri et al., 1960].

Основополагающие принципы восстановления лица по черепу, использующиеся нами в данной работе, разработаны в трудах Кольмана и Бехли [Kollmann, Buchly, 1898], М.М. Герасимова [Герасимов, 1949; 1955], а также его учеников и последователей в России [Лебединская, 1998; Никитин, 2009] и за рубежом [Prag, Neave, 1997; Taylor, 2000; Taylor, Angel, 1998; Wilkinson, 2004].
Сравнительная легкость выполнения графики (относительно работы над объемным вариантом восстановления внешности) привела к тому, что в традиции российской палеоантропологической науки серия графических реконструкций (опять-таки в основном в профильной норме) выполнялась по серии черепов из отдельного некрополя или группы могильников.

В антропологической науке серия графических антропологических реконструкций, выполненных в основном в профильной норме, позволяет перекинуть «мостик» от краниометрических характеристик серии к характеристике условно «живого» населения той или иной эпохи.

Сошлемся в данном контексте на ставшие уже классикой исследования в этой области Г.В. Лебединской [Лебединская, 1997]. В нашем арсенале также есть опыт создания галереи графических реконструкций по серии черепов [Нечвалода, 2010; 2015].

Применяя такой подход, исследователи понимают, что, как пишет Г.В. Лебединская: «Расодиагностические черты не наследуются комплексом, в связи с чем индивидуальное описание не может дать полного представления о принадлежности того или иного индивидуума к территориальному антропологическому типу или группе антропологических типов, которые сравнительно легко диагностируются для группы в среднем» [Лебединская, 1997 , с. 22].

Графическая реконструкция внешности в норме анфас долгое время была и остается до сих пор прерогативой криминалистов, занимающихся идентификацией личности по скелетированным останкам.

\section{Результаты \\ антропологической экспертизы}

Кург. 6, погр. 3. В свертке из крафт-бумаги находились кости мозговой коробки и фрагменты лицевого черепа, нижняя челюсть, отдельные зубы верхней и нижней челюстей. В процессе выполнения реставрации черепа удалось восстановить черепную коробку и 
собрать лицевой скелет. Сохранившиеся зубы были вставлены в соответствующие зубные альвеолы верхней и нижней челюстей и закреплены поливинилацетатной эмульсией. Зубная формула приобрела следующий вид. Череп принадлежал индивиду женского пола юношеского возраста (рис. 1). Присутствие третьих моляров на нижней челюсти в сочетании с незакрытым основно-затылочным синостозом дает нам возможность более точного определения возраста - 16-17 лет.

Проведенное палеопатологическое исследование зубочелюстного аппарата показало его сильную изношенность, не соответствующую диагностированному биологическому возрасту. Сохранившиеся резцы и клык на правой стороне нижней челюсти сточены до плащевого дентина. На нижней челюсти в области $\mathrm{M}_{1}$ справа и слева зафиксированы следы расплавления костной ткани альвеолярной области нижней челюсти, вызванного одонтогенным остеомиелитом (рис. 2,1,2).

По мнению Г.А. Кошкина [Кошкин, 1971], изучавшего изнашивание зубов в популяциях тагарской культуры Южной Сибири, основными триггерами данного процесса являются характер прикуса, особенности питания и участие зубов в трудовых процессах.

По его наблюдениям сильная стертость зубов была заметно выражена даже в постоянных зубах юношеского возраста. Им отмечалась стертость шестых зубов, когда седьмые находились в стадии прорезывания. В некоторых случаях им обнаружена почти полная стертость коронок зубов.

Наблюдаемый нами случай, зафиксированный на Зауральском материале эпохи поздней бронзы, относится к категории патологической стираемости и изношенности зубов в ювенильном возрасте.

Черепная коробка по соотношению продольного и поперечного диаметров мезокранная (табл. 1). По высотно-продольному указателю - ортокранная, по высотно-поперечному - акрокранная. В вертикальной норме имеет овоидную форму. Основание черепа среднеширокое и короткое. Затылок среднеширокий. Рельеф затылочной кости в области прикрепления мышц шеи не выражен, затылочный бугор отсутствует. Сосцевидный отросток слаборазвитый.
Лоб среднеширокий. Надпереносье и надбровные дуги имеют слабое развитие, что соотносится с ювенильным возрастом.

Скуловой диаметр был реконструирован по данным измерения на правой стороне черепа. Он составил весьма малую величину (124.0). Верхняя высота лица средняя (65.0). По пропорциям висцеральный скелет средний (мезопрозоп-мезен).

Измерение назомалярного угла показало уплощенность лица на орбитальном уровне: $146.3^{\circ}$ - величина, характерная для популяций монголоидного круга (свыше $138^{\circ}-$ монголоидность). Клыковая ямка средней глубины. Скуловая кость неширокая, грацильного строения. Высота и ширина носа средняя, по соотношению размеров наблюдается мезориния. Высоту и ширину переносья измерить не удалось в связи с постмортальными разрушениями области точки дакрион. Визуально переносье неширокое и невысокое. От носовых костей сохранилась только область корня носа на треть их длины. Учитывая морфологические особенности носового отростка верхней челюсти, сохранившегося с правой стороны, носовые кости были смоделированы с помощью твердого скульптурного пластилина по всей своей длине. Это позволило нам вычислить тригонометрическим способом угол выступания носа, который составил среднею величину $-24.0^{\circ}$. Нижний край грушевидной аппертуры притуплен, передненосовая ость разрушена, но, судя по морфологическим особенностям данной области черепа, имела слабое или среднее развитие.

Орбиты очень широкие и высокие. По указателю - мезоконхные. Угловая ширина нижней челюсти большая, со среднеразвитым макрорельефом в области гонионов. Высота симфиза, тела и толщина нижней челюсти в категории малых величин.

Для поиска ближайших аналогий физическому типу индивида из погр. 3 было выполнено сопоставление описанного черепа, краниометрические параметры которого с помощью коэффициентов полового диморфизма [Алексеев, Дебец, 1964] были переведены в «мужские» (табл. 1; столбец 2), с использованием формулы Гейнке. Сопоставление проводилось по одиннадцати линейным признакам (№ по Мартину - M1, M8, M9, M45, M;8, 
M51, M52, M54, M55, M77, M75 (1) и пяти указателям: продольно-поперечному M1/M8; скуловому M48/M45; носовому М54/М55; орбитному М52/M51; лобно-поперечному М9/M8. В качестве сравнительных были привлечены серии: сборная серия черепов срубно-алакульского типа, черепа алакульской культуры из Зауралья [Китов, 2011], материалы из могильника алакульцев Западного Казахстана Тасты-Бутак [Алексеев, Гохман, 1984], могильника Лаимберды в башкирском Зауралье [Hечвалода, 2016], черепа срубников Башкирии (суммарные данные) [Юсупов, 1989], черепа срубников лесостепного Поволжья [Шевченко, 1986].

В результате сравнения череп из погр. 3 кург. 6 могильника Березовка V оказался морфологически более близок черепам, составившим серию из могильника Лаимберды (рис. 3), и суммарной серии алакульцев Зауралья. Могильник эпохи поздней бронзы Лаимберды находится в Башкирском Зауралье (Баймакский район РБ). На одноименном поселении была во множестве обнаружена керамика срубно-алакульского облика, что позволило специалистам отнести данный памятник к синкретическим памятникам срубно-алакульского типа. Наиболее отдаленная - серия из Тасты-Бутака.

По черепу была выполнена графическая реконструкция внешнего облика в норме анфас. Утраченные части левой половины черепа были смоделированы графически (рис. 4)

Кург. 6, погр. 1, скелет 2. Погр. 1 в данном кургане является парным и потому вызывает закономерный неподдельный интерес в контексте неодновременных парных захоронений на широких пространствах от Южного Урала до Средней Азии, чему была посвящена отдельная публикация Я.В. Рафиковой $[\mathrm{Pa}-$ фикова, 2017]. Данная погребальная практика рассматривается многими исследователями как захоронения равноправных супругов.

К сожалению, в краниологических фондах отдела этнологии сохранился лишь неполный череп - мозговая коробка, которая также подверглась частичной реставрации, скуловые кости, крупный фрагмент левой верхней челюсти, нижняя челюсть.

Судя по развитию макрорельефа нейрокраниума, в частности затылочной кости, где фиксируется хорошее развитие верхних выйных линий и затылочного бугра (4 балла); височной кости - предельное развитие сосцевидного отростка (3 балла), а также надсосцевидного рельефа, наконец, лобной кости, где мы наблюдаем хорошее развитие области глабеллы (5 баллов), череп принадлежит индивиду мужского пола (рис. 5).

Состояние швов черепа и зубов, практически все из которых находились в альвеолах и имели небольшие следы стертости жевательной поверхности, позволяет нам говорить о возмужалом возрасте мужчины (20-25 лет; adultus).

При этом молодой мужчина, захороненный в парном погребении, обладал отменным здоровьем, судя по состоянию зубочелюстного аппарата. Все зубы нижней челюсти, полностью сохранившиеся, крепко сидят в зубных альвеолах, только на некоторых зубах ( $\mathrm{M}_{1}$, $\mathrm{M}_{2}$ справа) обнаружены небольшие следы отложения зубного камня.

На нижней челюсти справа зафиксировано явление гипердонтии - дополнительный, хорошо развитый моляр на месте второго премоляра (рис. 6).

В вертикальной норме череп ромбоидной формы. Во фронтальной норме свод черепа крышевидный, с сильно развитыми теменными буграми. Лобная кость несет на себе следы зарастания sutura metopica в виде несильно выраженного сагиттального валика.

По соотношению диаметров черепной коробки череп мезокранный (76.2) при большом поперечном и очень большом продольном диаметрах. По высотно-продольному указателю - ортокран, по высотно-поперечному метриокран, то есть обладатель средневысокой мозговой коробки при среднем высотном диаметре черепа. Лоб среднеширокий. По лобно-поперечному указателю - стенометоп (узколобый) (табл. 2). Особо стоит отметить уплощенность лицевого скелета на орбитальном уровне $\left(142.5^{\circ}\right)$.

Средний модуль ряда нижних моляров (m cor M 1-2) составил величину 10.2. Из одонтоскопических признаков фиксируются узоры Y 4 на $\mathrm{M}_{1}$ и +4 на $\mathrm{M}_{2}$.

Кург. 6, погр. 5. Череп принадлежал зрелому мужчине (40-50 лет) судя по состоянию 
зубочелюстного аппарата нижней челюсти и сохранившихся фрагментов левой и правой верхней челюсти и степени облитерации швов эктокрана (рис. 7). Череп средней массивности с ярко выраженным макрорельефом затылочной кости (затылочный бугор имеет предельное развитие - 5 баллов, а также предельное развитие верхних выйных линий). Сосцевидный отросток - 3 балла. По черепному указателю долихокран (73.0). По соотношению продольного и высотного (М17) диаметров ортокран, поперечного и высотного - метриокран. Таким образом, свод черепа умеренно высокий при малом высотном диаметре. По лобно-поперечному указателю наблюдается эуриметопия - широколобость. Лицевой скелет сильно уплощен на орбитальном уровне, о чем свидетельствует величина назомалярного угла $\left(150.0^{\circ}\right)$.

\section{Заключение}

1. Стертость зубов молодой женщины, захороненной в погр. 3 кург. 6 Березовского V, не соответствует ее биологическому возрасту, диагностированному по черепу, прежде всего потому, что это не закрытый затылочно-основной синхондроз, швы черепа без следов облитерации. Зубочелюстной аппарат женщины носит следы сильнейшей изношенности зубов, вероятно, в результате их участия в трудовой деятельности.

2. В краниологическом типе женщины выявляется монголоидный компонент. Это уплощенность области переносья, высокие орбиты, слабо выступающий нос, уплощенность лица на орбитальном уровне.
3. Поиск ближайших аналогий физическому типу населения, погребенному в кург. 6 Березовского V могильника с помощью метода Гейнке, несмотря на всю условность процедуры с переводом женского черепа в «мужской» с помощью коэффициентов полового диморфизма, позволяют судить о его морфологической близости к черепам из синкретического срубно-алакулского могильника Лаимберды в Башкирском Зауралье и объединенной серии черепов алакульской культуры из Зауралья.

4. На черепах мужчин из этого могильника назомалярный угол имеет большие значения, что дает возможность судить о присутствии монголоидного компонента в физическом типе погребенных в кург. 6 Березовского V могильника.

\section{ПРИМЕЧАНИЕ}

${ }^{1}$ Статья подготовлена при поддержке подпрограммы «Памятники материальной и духовной культуры в современной информационной среде» (I.25) проект № 255 «Парные разнополые погребения эпохи бронзы от Урала до Индостана как источник по реконструкции семейно-брачной и социальной структуры» в рамках объединенной программы Президиума РАН «Социально-гуманитарные аспекты устойчивого развития и обеспечения стратегического прорыва России».

This paper was supported by the Subprogram "Material and Spiritual Artifacts in Modern Information Medium" (I.25), project no. 255 "Bronze Age Burials of Different-Gender Couples from the Urals to Hindustan as a Source of Reconstructing FamilyMarriage and Social Structure", in terms of the RAS Presidium's Joint Program "Social and Humanitarian Aspects of Sustainable Development and Ensuring the Strategic Breakthrough of Russia”. 


\section{ИЛЛюСТРАЦИИ}
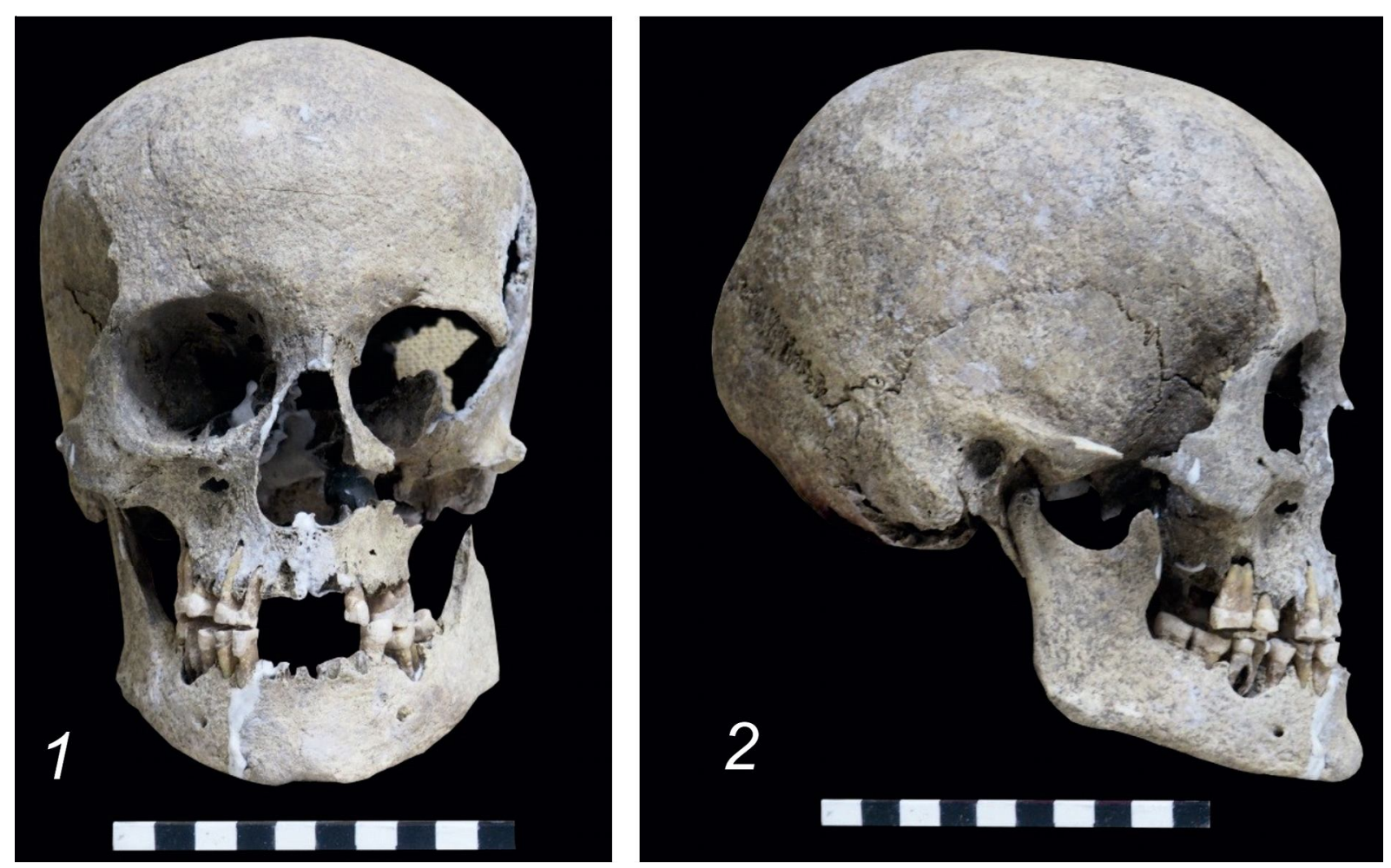

Рис. 1. Череп женщины из кург. 6, погр. 3 в фациальной и боковой нормах:

1 - фациальная норма; 2 - боковая норма

Fig. 1. Skull of a woman from the mound 6, burial 3 in the facial and lateral norms: 1 - facial norm; 2 - lateral norm
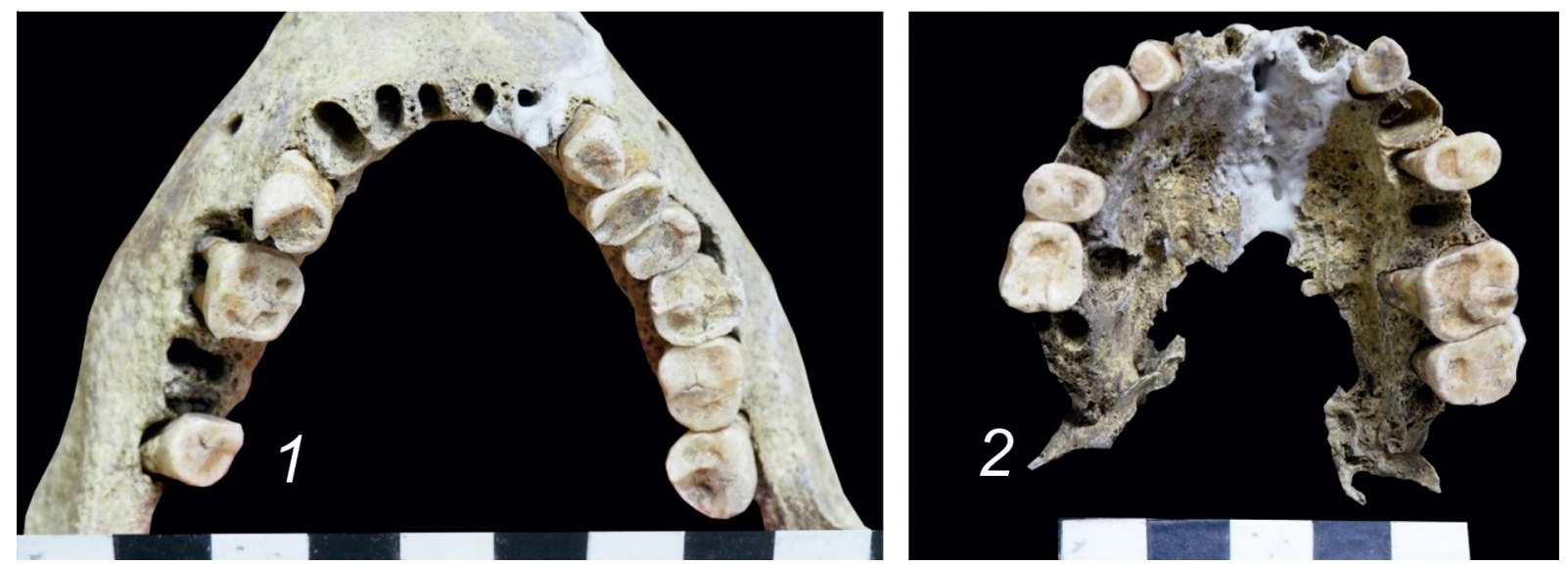

Рис. 2. Состояние зубочелюстного аппарата молодой женщины из кург. 6, погр. 3.

Сильная степень стертости и изношенности зубов в результате их участия в трудовой деятельности:

1 - нижняя челюсть; 2 - верхняя челюсть

Fig. 2. State of the dental apparatus of a young woman from the mound 6, burial 3.

Strong degree of wear and tear of teeth as a result of participation in labor activity:

$$
1 \text { - mandibula; } 2 \text { - maxilla }
$$


A.I. Nechvaloda. Craniological Materials of the Late Bronze Age from the Berezovsky V Kurgan Cemetery

Таблииа 1. Некоторые индивидуальные краниометрические параметры и индексы женского черепа из кург. 6, погр. 3 Березовского $V$ курганного могильника

Table 1. Some individual craniometrics parameters and indices of the female skull from Berezovsky V kurgan cemetery, kurgan 6, burial 3

\begin{tabular}{|c|c|c|c|}
\hline $\begin{array}{c}\text { No } \\
\text { Martin }\end{array}$ & Признак & $\begin{array}{l}\text { Значение } \\
\text { признака }\end{array}$ & $\begin{array}{c}\text { Значение } \\
\text { признака } \\
\text { Ж ? М }\end{array}$ \\
\hline 1 & Продольный диаметр & 173.0 & 181.4 \\
\hline 5 & Длина основания черепа & 100.0 & - \\
\hline 8 & Поперечный диаметр & 135.0 & 139.9 \\
\hline 9 & Наименьшая ширина лба & 94.0 & 97.0 \\
\hline 10 & Наибольшая ширина лба & - & - \\
\hline 11 & Ширина основания черепа & 121.0 & - \\
\hline 12 & Ширина затылка & 105.0 & - \\
\hline 17 & Высотный диаметр от $b a$ & 135.0 & - \\
\hline 38 & Емкость черепа/см ${ }^{3}$ & 1303.8 & - \\
\hline 40 & Длина основания лица & 92.0 & - \\
\hline 43 & Средняя ширина лица & - & - \\
\hline 45 & Скуловой диаметр & $124.0(?)$ & 132.9 \\
\hline 47 & Полная высота лица & 109.0 & - \\
\hline 48 & Верхняя высота лица & 65.0 & 69.9 \\
\hline 51 & Ширина орбиты от $m f$ & $44.0(d)$ & 45,8 \\
\hline 52 & Высота орбиты & $36.0(d)$ & 36.2 \\
\hline 54 & Ширина носа & $25.0(?)$ & 26.0 \\
\hline 55 & Высота носа & 49.0 & 52.0 \\
\hline 65 & Мыщелковая ширина mandibula & - & - \\
\hline 66 & Угловая ширина mandibula & 100.0 & - \\
\hline 69 & Высота симфиза mandibula & 28.0 & - \\
\hline $75(1) *$ & Угол выступания носа & $24.2 *$ & 28.2 \\
\hline 77 & Назомалярный угол & 146.3 & 146.3 \\
\hline$<\mathrm{Zm}$ & Зигомаксиллярный угол & - & - \\
\hline SS & Симотическая высота & 3.7 & - \\
\hline $\mathrm{SC}$ & Симотическая ширина & 6.0 & - \\
\hline$<\mathrm{S}$ & Симотический угол & 78.0 & - \\
\hline DS & Дакриальная высота & - & - \\
\hline $\mathrm{DC}$ & Дакриальная ширина & - & - \\
\hline$<\mathrm{D}$ & Дакриальный угол & & - \\
\hline $\mathrm{S}$ & Высота изгиба скуловой кости по Wo & 8.0 & - \\
\hline \multirow[t]{2}{*}{$\mathrm{C}$} & Ширина скуловой кости по Wo & 50.0 & - \\
\hline & Указатель & $\begin{array}{c}\text { Значение } \\
\text { указателя }\end{array}$ & \\
\hline $1: 8$ & Продольно-поперечный & 78.0 & 77,1 \\
\hline $17: 1$ & Высотно-продольный & 78.0 & - \\
\hline $17: 8$ & Высотно-поперечный & 100.0 & - \\
\hline $9: 8$ & Лобно-поперечный & 54.3 & 69,3 \\
\hline 9:45 & Лобно-скуловой & 75.8 & - \\
\hline $40: 5$ & Выступания лица & 92.0 & - \\
\hline $48: 45$ & Верхний лицевой & 52.4 & 52,6 \\
\hline $48: 47$ & Лицевой & 87.9 & - \\
\hline $52: 51$ & Орбитный & 81.8 & 79.0 \\
\hline $54: 55$ & Носовой & 51.0 & 50.0 \\
\hline SS:SC & Симотический & 61.6 & - \\
\hline DS:DC & Дакриальный & - & - \\
\hline $\mathrm{S}: \mathrm{C}$ & Изгиба скуловой кости & 16.0 & - \\
\hline
\end{tabular}

Примечание. * Угол выступания носа вычислен тригонометрически. 


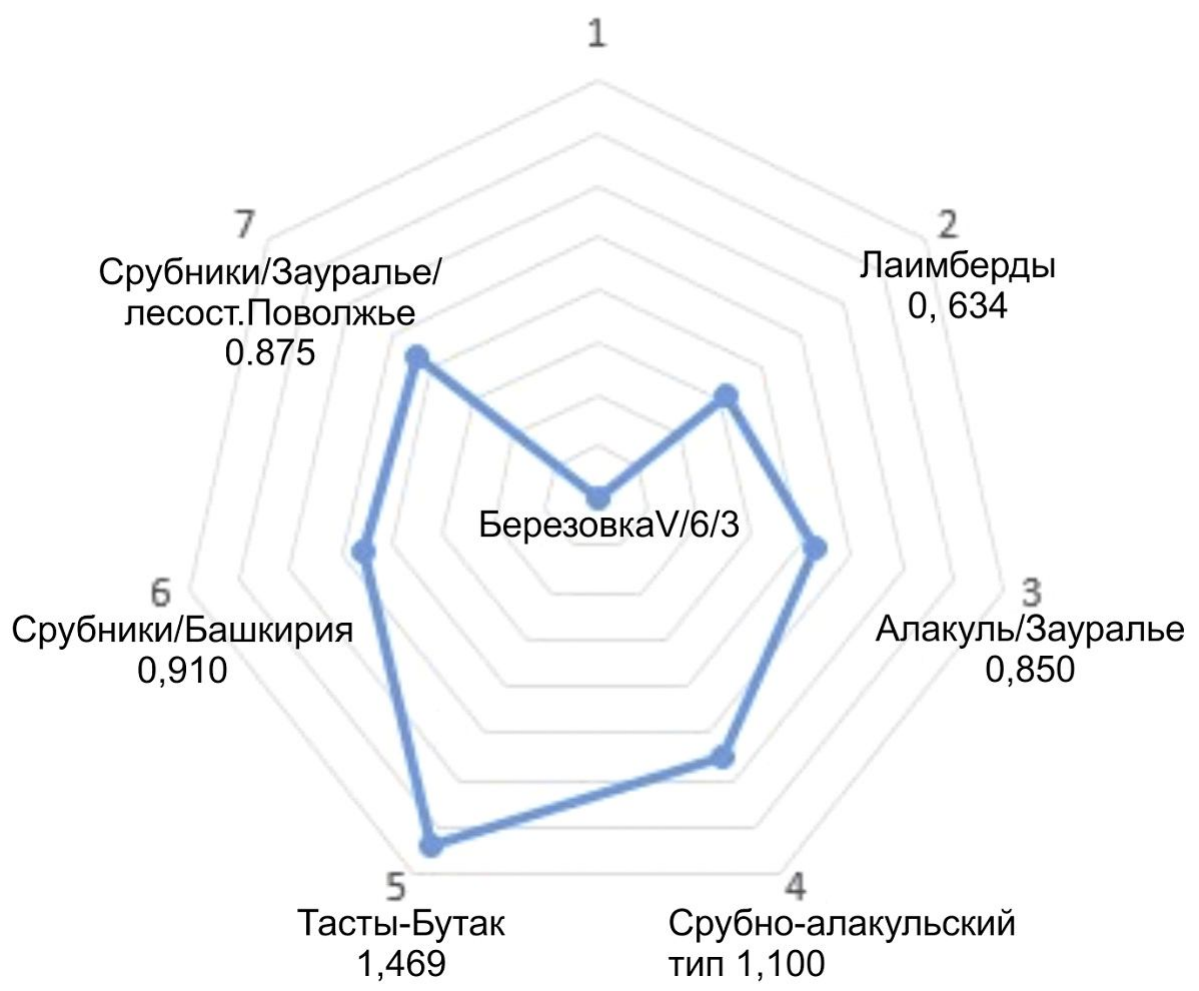

Рис. 3. График, демонстрирующий результат сопоставления серий по формуле Гейнке

Fig. 3. The graph that shows the result of comparing the series according to the Heinke formula 
A.I. Nechvaloda. Craniological Materials of the Late Bronze Age from the Berezovsky V Kurgan Cemetery
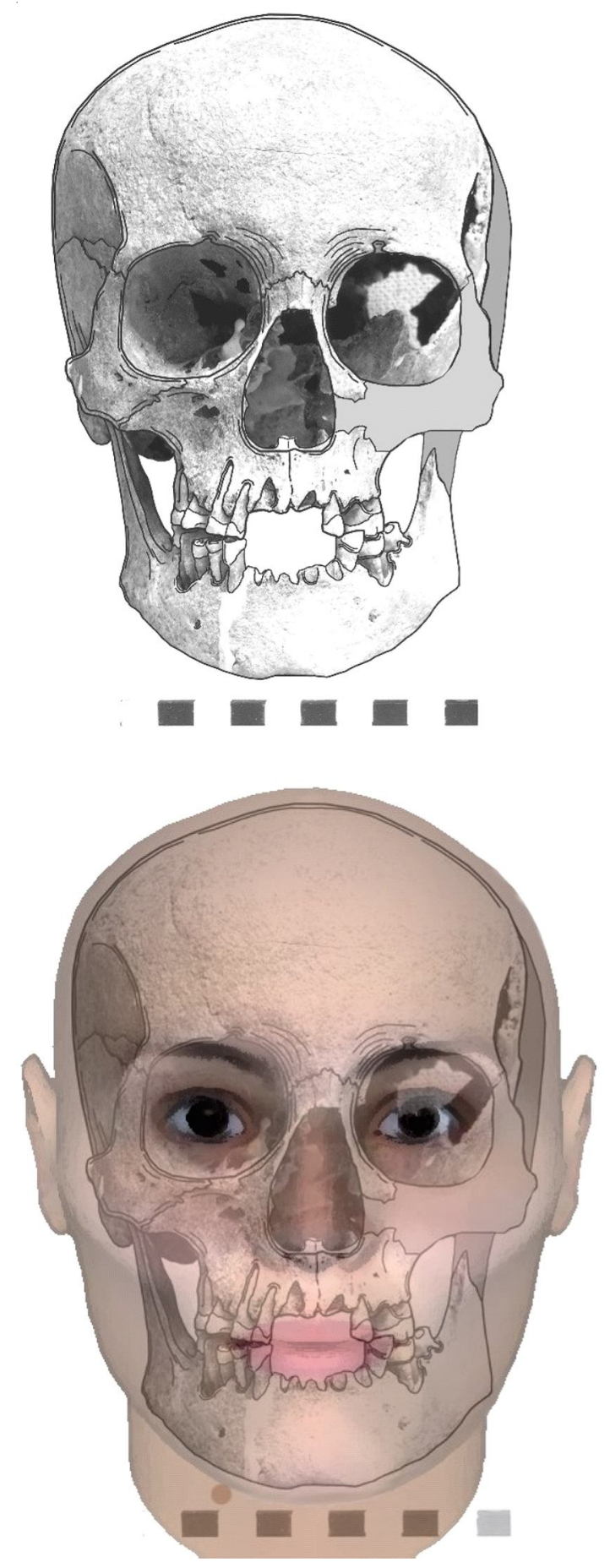

Рис. 4. Этапы графической реконструкции лица по черепу женщины из кург. 6, погр. 3
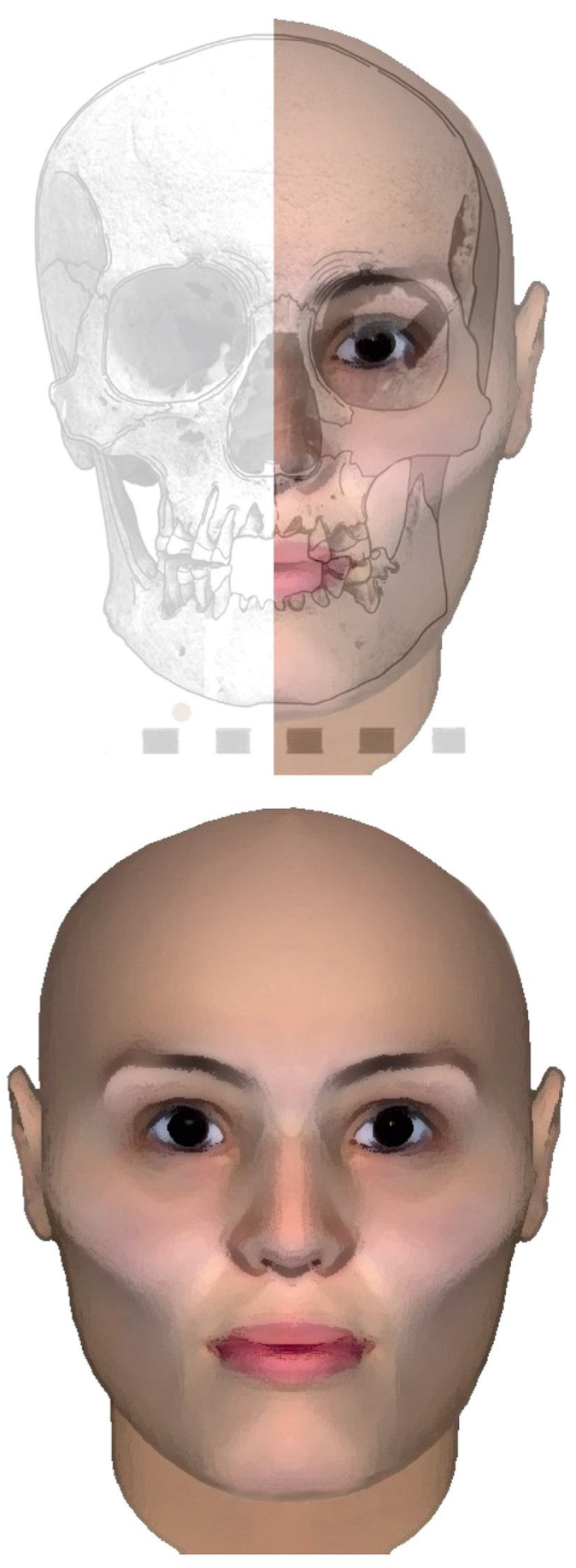

Fig. 4. Stages of graphic reconstruction of the face on the skull of a woman from barrow 6, burial 3 
А.И. Нечвалода. Краниологические материалы эпохи поздней бронзы из Березовского V курганного могильника
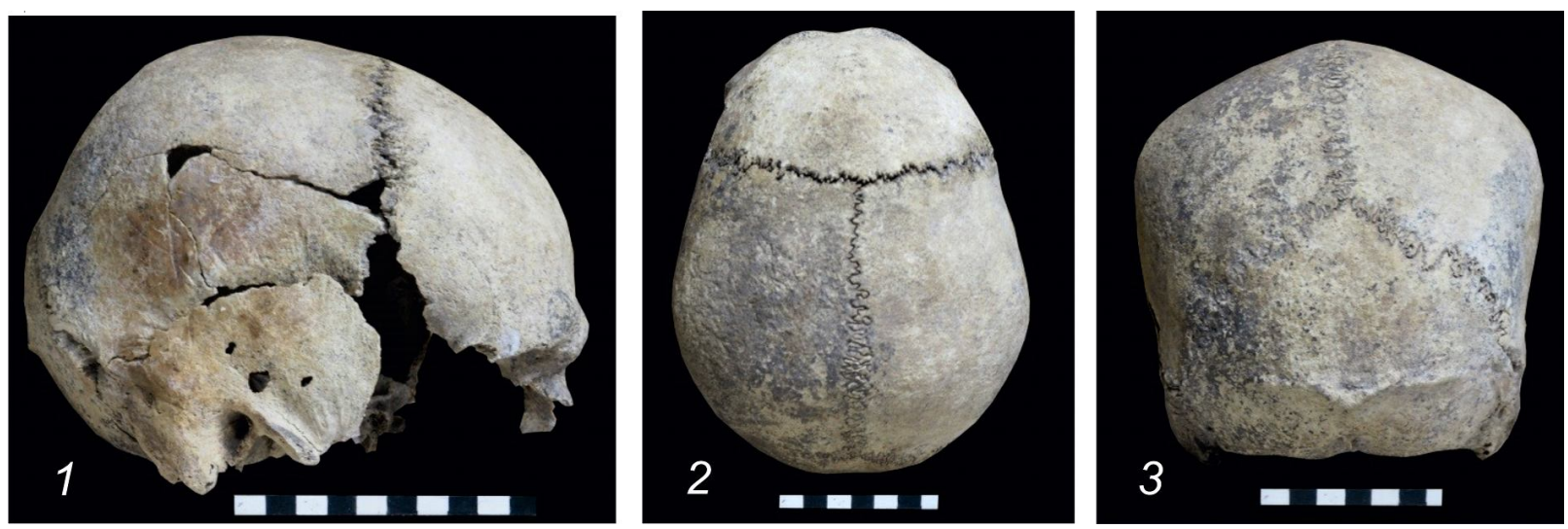

Рис. 5. Череп молодого мужчины из кург. 6, погр. 1, скелет 2:

1 - боковая норма; 2 - вертикальная норма; 3 - затылочная норма

Fig. 5. Skull of a young man from mound 6, burial 1, skeleton 2:

1 - lateral norm; 2 - vertical norm; 3 - occipital norm

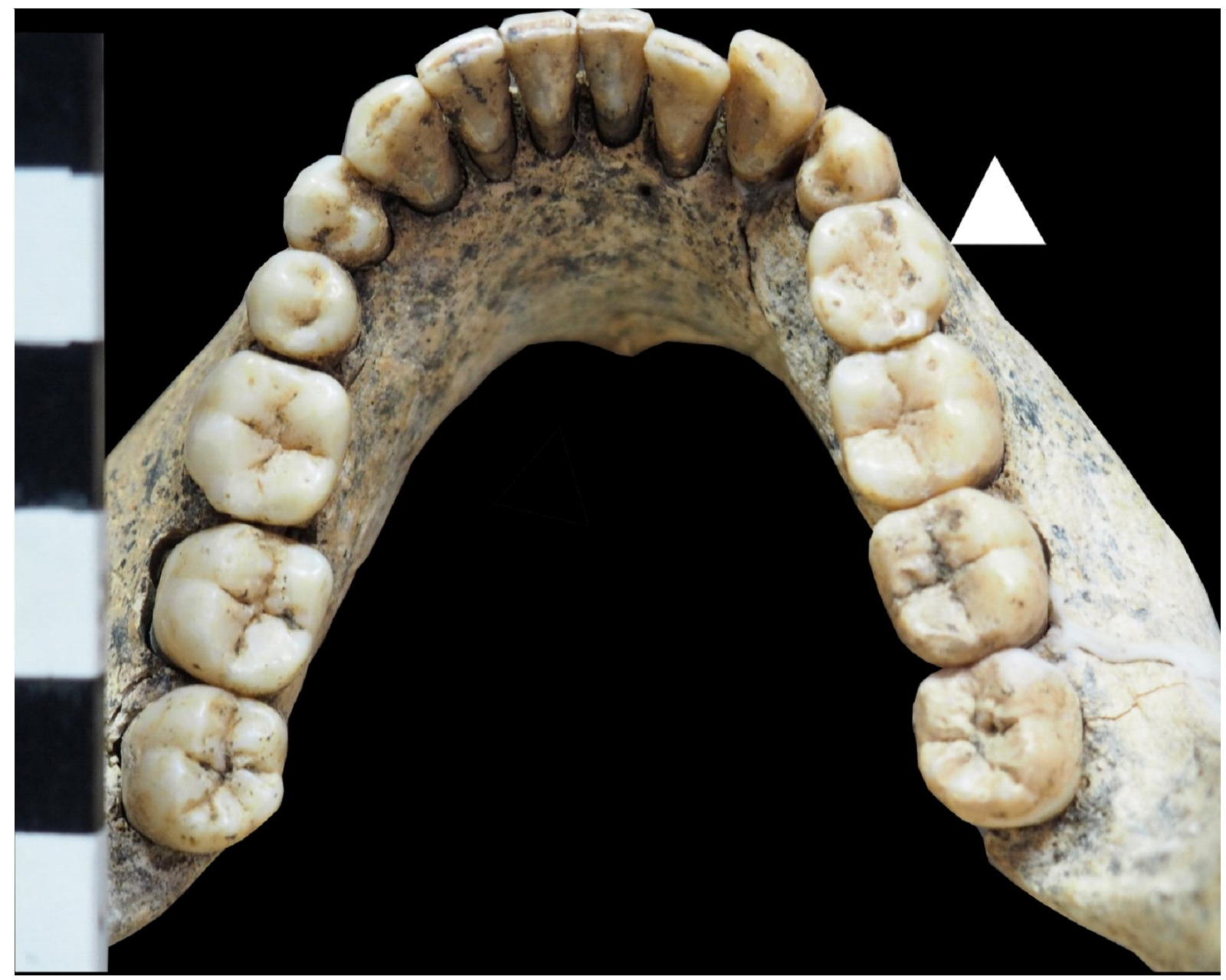

Рис. 6. Нижняя челюсть мужчины из погр. 1 с явлением гипердонтии: дополнительный коренной зуб указан стрелкой

Fig. 6. The mandibular of a man from burial 1 with the phenomenon of hyperdontia: an additional molar is indicated by an arrow 
A.I. Nechvaloda. Craniological Materials of the Late Bronze Age from the Berezovsky V Kurgan Cemetery

Таблица 2. Некоторые индивидуальные краниометрические параметры и индексы мужских черепов из Березовского курганного могильника

Table 2. Some individual craniometrics parameters and indices of the male skull from Berezovsky V kurgan cemetery, kurgan 3

\begin{tabular}{|c|l|c|c|}
\hline $\begin{array}{c}\text { No } \\
\text { Martin }\end{array}$ & \multicolumn{1}{|c|}{ Признак } & $\begin{array}{c}\text { Кург. 6/ } \\
\text { погр. 1/ } \\
\text { скелет 2 }\end{array}$ & $\begin{array}{c}\text { Кург. 6/ } \\
\text { погр. 5 }\end{array}$ \\
\hline 1 & Продольный диаметр & 194.0 & 182.0 \\
\hline 5 & Длина основания черепа & 111.0 & 100.0 \\
\hline 8 & Поперечный диаметр & 148.0 & 133.0 \\
\hline 9 & Наименьшая ширина лба & 95.0 & 96.0 \\
\hline 10 & Наибольшая ширина лба & 121.0 & 110.0 \\
\hline 11 & Ширина основания черепа & 120.0 & 126.0 \\
\hline 12 & Ширина затылка & 120.0 & 112.0 \\
\hline 17 & Высотный диаметр от $b a$ & 139.0 & 129.0 \\
\hline 77 & Назомалянный угол & 142.5 & 150.0 \\
\hline $8: 1$ & Продольно-поперечный & 76.2 & 73.0 \\
\hline $17: 1$ & Высотно-продольный & 71.6 & 70.8 \\
\hline $17: 8$ & Высотно-поперечный & 93.9 & 96.9 \\
\hline $9: 8$ & Лобно-поперечный & 64.2 & 72.2 \\
\hline $9: 10$ & Лобный & 78.5 & 87.2 \\
\hline
\end{tabular}
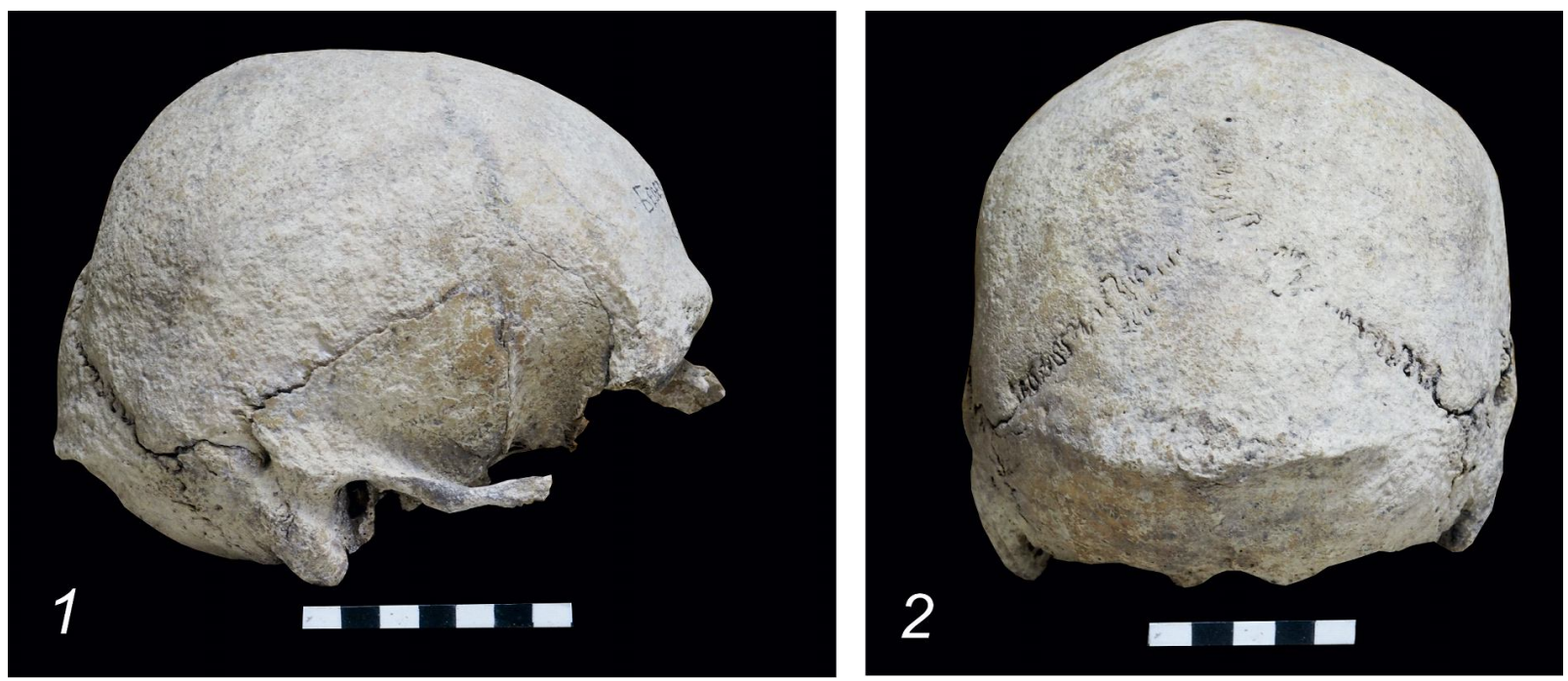

Рис. 7. Череп мужчины из кург. 6, погр. 5:

1 - боковая норма; 2 - затылочная норма

Fig. 7. Skull of a man from the mound 6, burial 5:

1 - lateral norm; 2 - occipital norm 


\section{СПИСОК ЛИТЕРАТУРЫ}

Алексеев В. П., Гохман И. И., 1984. Антропология Азиатской части СССР. М. : Наука. 208 с.

Алексеев В. П., Дебец Г. Ф., 1964. Краниометрия. Методика антропологических исследований. М. : Наука. 128 с.

Герасимов М. М., 1949. Основы восстановления лица по черепу. М. : Советская наука. 187 с.

Герасимов М. М., 1955. Восстановление лица по черепу (современный и ископаемый человек) // Труды института этнографии АН СССР. Новая Серия. Т. XXXVIII. М. : Изд-во АН СССР. 585 с.

Китов Е. П., 2011. Палеоантропология населения Южного Урала эпохи бронзы : автореф. дис. ... канд. ист. наук. М. 26 с.

Кошкин Г. А., 1971. Состояние зубов и челюстей древних жителей Южной Сибири (Тагарская. культура VIIII вв. до н. э.) : автореф. дис. ... канд. мед. наук. Казань. 23 с.

Лебединская Г. В., 1997. Антропологическая реконструкция внешнего облика людей, оставивших могильники Сахтыш, Ивановское, Ловцы и озеро Ловецкое // Неолит лесной полосы Восточной Европы (Антропология Сахтышских стоянок). М. : Науч. мир. С. 22-26.

Лебединская Г. В., 1998. Реконструкция лица по черепу. М. : Старый Сад. 125 с.

Нечвалода А. И., 2010. Графическая реконструкция внешнего облика людей по краниологическим материалам энеолитических могильников Хвалынск I, Хвалынск II, Хлопков бугор // Хвалынские энеолитические могильники и хвалынская энеолитическая культура. Исследование материалов. Самара : СРОО ИЭКА “Поволжье”. С. 518-563.

Нечвалода А. И., 2015. Лицом к Лицу. Альбом скульптурных и графических антропологических реконструкций. М. : Старый Сад. 115 с.

Нечвалода А. И., 2016. К антропологии населения эпохи бронзы Башкирского Зауралья: черепа из курганного могильника Лаимберды // Историко-культурные процессы на Южном Урале: проблемы изучения и сохранения культурного наследия : материалы Всерос. науч.-практ. конф., посвящ. 70-летию со дня рождения Н.Г. Рутто. Уфа : Диалог. С. 174-190.

Никитин С. А., 2009. Пластическая реконструкция портрета по черепу // Некрополь русских великих княгинь и цариц в Вознесенском соборе Московского Кремля. Т. 1. М. : Московский Кремль. С. 137-167.

Рафикова Я. В., 2017. Погребение 1 кургана 6 Березовского V могильника в контексте неодновременных парных погребений эпохи поздней бронзы Южного Урала и Средней Азии // Развитие гуманитарной науки в регионах России : материалы Междунар. науч. конф., посвящ. 85-летию Института истории, языка и литературы Уфимского научного центра РАН. Уфа : ИИЯЛ УНЦ РАН. С. 337-339.

Федоров В. У., Рафикова Я. В., 1996. Березовский V курганный могильник в Зауралье // Башкирский край. Вып. 6. Уфа : Литера. С. 49-71.

Шевченко А. В., 1986. Антропология населения южнорусских степей в эпоху бронзы // Антропология современного и древнего населения Европейской части СССР. Л. : Наука. С. 121-216.

Юсупов Р. М., 1989. Антропология населения срубной культуры Южного Приуралья // Материалы по эпохе бронзы и раннего железа Южного Урала и Нижнего Поволжья. Уфа : БНЦ УрО АН СССР. С. 127-138.

Martin R., 1914. Lehrbuch der Anthropologie in systematischer Darstellung mit besonderer Berücksichtigung der anthropologischen Methoden für Studierende Ärzte und Forschungsreisende. Jena : Gustav Fischer. $1181 \mathrm{~S}$.

Meindl R. S., Lovejoy C. O., 1985. Ectocranial Suture Closure: a Revised Method for the Determination of Skeletal Age at Death Based on the Lateral-Anterior Sutures // American Journal of Physical Anthropology. № 68. P. 57-66.

Kollmann J., Buchly W., 1898. Die Persistenz der Rassen und die Rekonstruktion der Physiognomie prahistorischer Schadel // Archives fur Anthropologie. № 25. P. 329-359.

Nemeskéri J., Harsányi L., Acsádi Gy., 1960. Methodenzur Diagnose des Lebensalters von Skelettfunden // Anthropologischer Anzeiger. №24. P. 103-115.

Prag J., Neave R., 1997. Making Faces: Using Forensic and Archaeological Evidence. L. : British Museum. 256 p.

Taylor K. T., 2000. Forensic Art and Illustration. Boca Raton : CRC Press. 580 p.

Taylor R. G., Angel C., 1998. Facial Reconstruction and Approximation // J.G. Clement, D.L. Ranson (Eds). Craniofacial Identification in Forensic Medicine. L. : Arnold. P. 177-185.

Wilkinson C., 2004. Forensic Facial Reconstruction. Cambridge : Cambridge University Press. 292 p. 


\section{REFERENCES}

Alekseev V.P., Gohman I.I., 1984. Antropologiya Aziatskoy chasti SSSR [Anthropology of the Asian Part of the USSR]. Moscow, Nauka Publ. 208 p.

Alekseev V.P., Debets G.F., 1964. Kraniometriya. Metodika antropologicheskih issledovaniy [Craniometry. Methods of Anthropological Research]. Moscow, Nauka Publ. 128 p.

Gerasimov M.M., 1949. Osnovy vosstanovleniya litsa po cherepu [Basics of Facial Reconstruction on the Skull]. Moscow, Sovetskaya nauka Publ. 187 p.

Gerasimov M.M., 1955. Vosstanovlenie litsa po cherepu (sovremennyy i iskopaemyy chelovek) [Restoration of the Face by the Skull (Modern and Fossil Man)]. Trudy instituta etnographii AN SSSR. Novaya Seriya, vol. XXXVIII. Moscow, Academy of Sciences of the USSR. 585 p.

Kitov E.P., 2011. Paleoantropologiya naseleniya Yuzhnogo Urala epohi bronzy: avtoref. dis. ... kand. ist. nauk [Paleoanthropology of the Population of the Southern Urals of the Bronze Age. Cand. hist. sci. abs. diss.] Moscow. 26 p.

Koshkin G.A., 1971. Sostoyanie zubov i chelyustey drevnih zhiteley Yuzhnoy Sibiri (Tagarskaya kul tura VII-II vv. do n. e.): avtoref. dis. ... kand. med. nauk [The Condition of the Teeth and Jaws of the Ancient Inhabitants of Southern Siberia (Tagar Culture of the VII-II Centuries BC). Cand. med. sci. abs. diss.] Kazan'. 23 p.

Lebedinskaya G.V., 1997. Antropologicheskaya rekonstruktsiya vneshnego oblika lyudey, ostavivshih mogil'niki Sahtysh, Ivanovskoe, Lovtsy i ozero Lovetskoe [Anthropological Reconstruction of the External Appearance of People who Left the Cemeteries of Sakhtysh, Ivanovskoye, Lovtsy and Lake Lovetskoye]. Neolit lesnoy polosy Vosochnoy Evropy: (Antropologiya Sahtyshskih stoyanok) [Neolithic Forest Zone of Eastern Europe: (Anthropology of Sakhtysh Sites)]. Moscow, Nauchniy mir Publ., pp. 22-26.

Lebedinskaya G.V., 1998. Rekonstruktsiya litsa po cherepu [Reconstruction of the Face on the Skull]. Moscow, Staryy Sad Publ. 125 p.

Nechvaloda A.I., 2010. Graficheskaya rekonstruktsiya vneshnego oblika lyudey po kraniologicheskim materialam eneoliticheskih mogil'nikov Hvalynsk I, Hvalynsk II, Hlopkov bugor [Graphic Reconstruction of the External Appearance of People on Craniological Materials of the Eneolithic Cemeteries of Khvalynsk I, Khvalynsk II, Khlopkov Bugor]. Hvalynskie eneoliticheskie mogil'niki i hvalynskaya eneoliticheskaya kul'tura. Issledovanie materialov [Khvalynsk Eneolitic Cemeteries and Khvalynsk Eneolitic Culture. Material Research]. Samara, SRPO HECA «Povolzje», pp. 518-563.

Nechvaloda A.I., 2015. Litsom k Litsu. Al'bom skul'pturnyh i graficheskih antropologicheskih rekonstruktsiy. [Face-to-Face. Album of Sculptural and Graphic Anthropological Reconstructions]. Moscow, Staryy Sad Publ. 115 p.

Nechvaloda A.I., 2016. K antropologii naseleniya epohi bronzy Bashkirskogo Zaural'ya: cherepa iz kurgannogo mogil'nika Laimberdy [Anthropology of the Population of the Bronze Age Bashkir Trans-Urals Region: the Skull of Kurgan Cemetery Laimberdy]. Istoriko-kul turnye protsessy na Yuzhnom Urale: problemy izucheniya i sohraneniya kul turnogo naslediya: materialy Vseros. nauch.-prakt. konf., posvyashch. 70-letiyu so dnya rozhdeniya N.G. Rutto [Historical-Cultural Processes in the South Urals: Problems of Study and Conservation of Cultural Heritage. Materials of All-Russian Scientific-Practical Conference Dedicated to the 70th anniversary from the Birthday N. G. Rutto]. Ufa, Dialog Publ., pp. 174-190.

Nikitin S.A., 2009. Plasticheskaya rekonstruktsiya portreta po cherepu [Plastic Reconstruction of the Portrait on the Skull]. Nekropol' russkih velikih knyagin' $i$ tsarits v Voznesenskom sobore Moskovskogo Kremlya [Necropolis of Russian Grand Duchesses and Tsarinas in the Voznesenskiy Cathedral of the Moscow Kremlin], vol. 1. Moscow, Moscow Kremlin, pp. 137-167.

Rafikova Ya.V., 2017. Pogrebenie 1 kurgana 6 Berezovskogo V mogil'nika v kontekste neodnovremennyh parnyh pogrebeniy epohi pozdney bronzy Yuzhnogo Urala i Sredney Azii [Burial 1, Kurgan 6 of Berezovskiy V Cemetery in the Context of the Duality of Paired Burials of the Late Bronze Age of the Southern Urals and Central Asia]. Razvitie gumanitarnoy nauki v regionah Rossii: materialy Mezhdunarodnoy nauchnoy konferentsii, posvyashchennoy 85-letiyu Federal'nogo gosudarstvennogo byudzhetnogo uchrezhdeniya nauki Institut istorii, yazyka i literatury Ufimskogo nauchnogo centra RAN [The Development of the Humanities in the Russian Regions. Materials of the International Scientific Conference Devoted to 85 Anniversary of Federal State Budget Institution of Science Institute of History, Language and Literature of Ufa Scientific Center RAS]. Ufa, IHLL USC RAS, pp. 337-339. 
Fedorov V.U., Rafikova Y.V., 1996. Berezovskiy V kurgannyy mogil'nik v Zaural'e [Berezovskiy V Kurgan Cemetery in the Trans-Urals]. Bashkirskiy kray [Bashkir Region], iss. 6. Ufa, Litera Publ., pp. 49-71.

Shevchenko A.V., 1986. Antropologiya naseleniya yuzhnorusskih stepey v epohu bronzy [Anthropology of the Population of the South Russian Steppes in the Bronze Age]. Antropologiya sovremennogo $i$ drevnego naseleniya Evropeyskoy chasti SSSR [Anthropology of the Modern and Ancient Population of the European Part of the USSR]. Leningrad, Nauka Publ., pp. 121-216.

Yusupov R. M., 1989. Antropologiya naseleniya srubnoy kul'tury Yuzhnogo Priural'ya [Anthropology of the Population of the Srubnaya Culture of the Southern Urals]. Materialy po epohe bronzy i rannego zheleza Yuzhnogo Urala i Nizhnego Povolzh'ya [Materials on the Bronze Age and Early Iron of the Southern Urals and the Lower Volga Region]. Ufa, BSC YuD AS USSR, pp. 127-138.

Martin R., 1914. Lehrbuch der Anthropologie in systematischer Darstellung mit besonderer Berücksichtigung der anthropologischen Methoden für Studierende Ärzte und Forschungsreisende. Jena, Gustav Fischer. $1181 \mathrm{~S}$.

Meindl R.S., Lovejoy C.O., 1985. Ectocranial Suture Closure: a Revised Method for the Determination of Skeletal Age at Death Based on the Lateral-Anterior Sutures. American Journal of Physical Anthropology, no. 68, pp. 57-66.

Kollann J., Buchly W., 1898. Die Persistenz der Rassen und die Rekonstruktion der Physiognomie prahistorischer Schadel. Archives fur Anthropologie, no. 25, pp 329-359.

Nemeskéri J., Harsányi L., 1960. Acsádi Gy. Methodenzur Diagnose des Lebensalters von Skelettfunden. Anthropologischer Anzeiger, no. 24, pp. 103-115.

Prag J., Neave R., 1997. Making Faces: Using Forensic and Archaeological Evidence. London, British Museum. $256 \mathrm{p}$.

Taylor K.T., 2000. Forensic Art and Illustration. Boca Raton, CRC Press. 580 p.

Taylor R.G., Angel C., 1998. Facial Reconstruction and Approximation. J.G. Clement, D.L. Ranson (Eds). Craniofacial Identification in Forensic Medicine. London, Arnold, pp. 177-185.

Wilkinson C., 2004. Forensic Facial Reconstruction. Cambridge, Cambridge University Press. 292 p.

\section{Information About the Author}

Aleksey I. Nechvaloda, Researcher of Department of Ethnology, Institute of History, Language and Literature, Ufa Federal Research Center of the Russian Academy of Sciences, Prosp. Oktyabrya, 71, 450054 Ufa, Russian Federation, striwolf@mail.ru, https://orcid.org/0000-0002-9904-7284

\section{Информация об авторе}

Алексей Иванович Нечвалода, научный сотрудник отдела этнологии Института истории, языка и литературы, Уфимский федеральный исследовательский центр Российской академии наук, просп. Октября, 71, 450054 г. Уфа, Российская Федерация, striwolf@mail.ru, https://orcid.org/0000-0002-9904-7284 